\title{
Intercontinental Triaenonychidae—-the case of Ceratomontia (Opiliones, Insidiatores)
}

\author{
Amanda Cruz Mendes and Adriano Brilhante Kury: Laboratório de Aracnologia, Departamento de Invertebrados, Museu \\ Nacional, Universidade Federal do Rio de Janeiro, Quinta da Boa Vista s/n, São Cristóvão 20.940-040, Rio de Janeiro, \\ RJ, Brazil. E-mail: amanda.mendes@gmail.com
}

\begin{abstract}
Among the 64 genera of Triaenonychinae Sørensen 1886 (Opiliones, Insidiatores), two are found in more than one continent: Ceratomontia Roewer 1915 and Nuncia Loman 1902, both occurring in South America, the former occurring also in South Africa, the latter in New Zealand. Until now there were 22 valid species of Ceratomontia, diagnosed mainly by the tarsal formula. In the present paper, a cladistic analysis was performed to test the monophyly of Ceratomontia and study its relationship with the South African triaenonychine genera Austromontia Lawrence 1931 and Monomontia Lawrence 1931. A total of 42 morphological characters were coded for 18 terminal taxa, 14 representing the genera Ceratomontia (from South America and South Africa), Austromontia and Monomontia as ingroup, and two species of Triaenonychinae from South America, one from South Africa and one Adaeinae Pocock 1902 from South Africa as outgroups. The analysis using heuristic search algorithms resulted in 12 most parsimonious trees $(\mathrm{L}=95, \mathrm{CI}=0.52, \mathrm{RI}=$ 0.66). The consensus hypothesis did not recover a monophyletic Ceratomontia, instead, the South African species constitute a clade with the Austromontia and Monomontia species. The Ceratomontia species from South America form a clade that is sister-group of the clade formed by the South African genera of the ingroup. The result shows that Ceratomontia is involved in a "Gondwanan relationship," but also includes other genera, suggesting that it is not a monophyletic group.
\end{abstract}

Keywords: Temperate Gondwana, South Africa, South America, Laniatores, cladistics

The harvestman family Triaenonychidae Sørensen 1886 (Opiliones) includes about 480 described species (Kury 2003). It is the third most diverse family of the suborder Laniatores Thorell 1876 and the most diverse of the infra-order Insidiatores Loman 1902 (sensu Kury 2003). It includes small-sized Laniatores and is characterized by the single claws of legs III-IV bearing at least one pair of lateral prongs. The family is mainly distributed in the former Temperate Gondwana, constituting the dominant opilionofauna in New Zealand, Madagascar, and South Africa, also occurring in Australia and southern South America. It also includes representatives in the Northern Hemisphere as the subfamilies Sclerobuninae Dumitrescu 1976, Paranonychinae Briggs 1971, both Nearctic - the latter also occurring in Japan, Kaolinonychinae Suzuki 1976 and Nippononychinae Suzuki 1976 both from Eastern Asia (Japan and Korea), and the species Fumontana deprehendor Shear 1977 currently assigned as a member of Triaenonychinae, from the eastern United States (Shear 1977, 1978; Thomas \& Hedin 2006). Although the allocation of those subfamilies endemic to the Holarctic region into Triaenonychidae has been recently challenged (Giribet \& Kury 2007); there is not yet any detailed study on this matter.

Among the 64 genera of Triaenonychinae Sørensen 1886, two have been reported to occur in more than one continent: Ceratomontia Roewer 1915 and Nuncia Loman 1902, both occurring in South America, the former occurring also in South Africa, the latter also in New Zealand. There are currently 22 valid species of Ceratomontia: 18 in South Africa, including the type species C. capensis Roewer 1915, and four occurring in Argentina, Uruguay and south of Brazil.

The genus, as with most genera described by the German arachnologist Carl Friedrich Roewer (e.g., Roewer 1915, 1923), is mainly diagnosed by the tarsal formula of the type species (= 2-3-3-3). Lawrence $(1931,1934,1937)$ emended Roewer's diagnosis (Roewer 1915) with some characters of the pedipalpus and described an additional 17 species in the genus from South Africa; one (C. hewitti Lawrence 1931) later synonymized by Starega (1992). Canals (1939) described the first South American species for the genus, C. argentina Canals 1939, justifying the generic allocation by the presence of all the characters assigned to Ceratomontia by Roewer (1915) and almost all the characters aggregated by Lawrence (1931) except for the number of tubercles in the anterior margin of the ventral surface of coxa I. Two other South American species were described in the genus by Maury \& Roig-Alsina (1985) and another by Maury (1999), also based mainly on the tarsal formula. Kauri (1961) divided the South African genera of Triaenonychinae into two groups: the Ceratomontia group, including 11 genera with a longitudinal band of fine granulation on the ventral surface of the pedipalpal femur, and the Roewerania group, including nine genera without the band. Kauri (1961) also noted the resemblance of the male genitalia between the genera Ceratomontia, Austromontia Lawrence 1931, and Monomontia Lawrence 1931 (Kauri 1961: 75) but the basic character used to identify the genera that are included in his key (since he did not provide diagnoses), is the tarsal counts.

This work aims to test the monophyly of Ceratomontia as an intercontinental genus and verify the relationship between it and two of the genera included in the Ceratomontia group sensu Kauri, Austromontia and Monomontia, given the resemblance of external morphology and genitalia among those taxa.

\section{METHODS}

The specimens studied herein are deposited in the following collections: American Museum of Natural History, New York (AMNH), Museu Nacional/Universidade Federal do Rio de Janeiro (MNRJ), Collection Helia Eller Monteiro Soares, formerly a private collection, today on behalf of MNRJ 


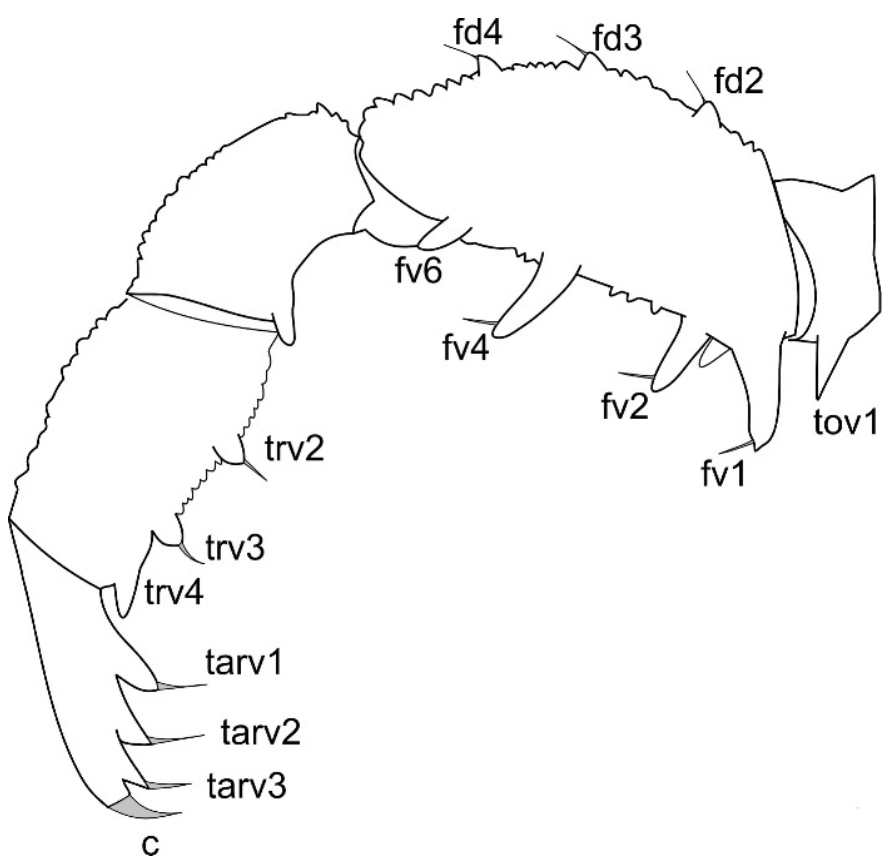

Figure 1.-Larifuga capensis. Retrolateral view of left pedipalpus. Setae terminology based on Hunt \& Hickman (1993:82, fig. 1); tov = trochanter ventral; $\mathrm{fd}=$ femur dorsal; $\mathrm{fv}=$ femur ventral; tarv $=$ tarsus retroventral; $\mathrm{c}=$ claw.

(HEMS), National Collection of Arachnida, Pretoria (NCA), Transvaal Museum, Pretoria (TM). The specimens were examined using a Wild Heerbrugg M8 stereomicroscope fitted with a camera lucida for drawings. Male genitalia were dissected and temporarily mounted on microscope slides with $1 \mathrm{~cm}$ coverslips supported by two slivers of broken coverslips, with two-three droplets of glycerol. They were observed using a Nikon E-200 compound microscope and after study returned to $75 \%$ ethanol in microvials kept with their respective specimen.

For pedipalpal setae we used the terminology created for Triaenonychidae by Hunt \& Hickman (1993), specified here in Fig. 1. For male genitalia we used Martenss (1986) terminology adapted by Hunt \& Hickman (1993). The figures of the present paper are referred to with a capital letter (i.e., "Fig."); figures of other papers are referred in lower case (i.e., "fig.").

Cladistic Analysis. - The ingroup consists of the type species of Ceratomontia and two other species occurring in South Africa as well as all four species occurring in South America (Argentina, south of Brazil, and Uruguay), besides three species of Austromontia and four of Monomontia. The outgroup is composed of two genera of South American Triaenonychinae, one of the South African Triaenonychinae and one representative of a South African genus of Adaeinae Pocock 1902. Table 1 provides the list of species used as terminals in the analysis, indicating their distribution and source of information used.

A total of 42 morphological characters were coded for 18 terminal taxa. The characters were treated as unordered and the polarization was made a posteriori, resulting from the rooting of the diagrams obtained by the parsimony analysis (Nixon \& Carpenter 1993). The coding for the terminals is shown in Table 2. An analysis using heuristic search algorithms with random addition-sequence (1000 replicates) and with equal weights and tree-bisection-reconnection (TBR) branch swapping was performed using the program NONA version 2.0 (Goloboff 1993c). Branch-support was evaluated through Bremer support (Bremer 1994) and bootstrap (Felsenstein 1985), both performed using NONA, via WinClada (Nixon 2002) in the case of bootstrap analysis, which was made with 2000 replicates with TBR swapping. We studied the distribution and optimization of the characters also through the program WinClada.

We also performed an analysis under implied weights using the program PIWE version 3.0 (Goloboff 1993a, b). As long as there is not a consensus in the literature in respect to the adequate value of the concavity constant $k$ (e.g., Turner \& Zandee 1995), we conducted the analyses with $k=1-6$ to observe the effect of the constant variation over the topology of the trees. The evaluation of stability of results through different parameters, such as different concavity values $(k)$, is comparable to a sensitivity analysis (Wheeler 1995) used in molecular analyses. This was done before by other authors in phylogenies using morphological data (Prendini 2003; de Bivort \& Giribet 2004). The analyses using implied weighting were also performed using heuristic search algorithms and TBR branch swapping.

\section{CLADISTIC ANALYSIS}

Characters. - The characters used in the analysis are listed below.

\section{Dorsal structures}

1. Anterior margin, ornamentation of tubercles, (0) absent; (1) present (Maury \& Roig-Alsina 1985:fig.18).

2. Anterior margin, number of tubercles, (0) two; (1) three; (2) four; (3) five.

3. Eyemound, length in relation to the width, (0) much larger, at least twice as large (Fig. 2A, B; Maury \& Roig-Alsina 1985:fig. 17); (1) less than twice as large (Fig. 2C; Maury \& Roig-Alsina 1985: fig. 19).

4. Eyemound, median spine aspect, (0) continuous with the eyemound (conic aspect) (Fig. 2A); (1) independent of the eyemound base (Fig. 2B).

5. Eyemound, direction, (0) upwards (dorsally pointed) (Fig. 2B); (1) slightly anteriorly directed; (2) conspicuously anteriorly directed (Fig. 2A)

6. Eyemound, groove between eyemound and the posterior region of the carapace, (0) absent; (1) present (Kauri 1962:fig. 49A).

7. Mesotergal areas, definition, (0) poorly defined (shallow); (1) well defined (deep).

8. Mesotergal areas $I-I V$, pair of tubercles, (0) present; (1) absent.

9. Posterior margin and free tergites, kind of ornamentation, (0) row of conspicuous conical tubercles or apophyses; (1) row of small granules.

Appendages

10. Chelicera, basichelicerite, bulla, (0) weakly defined; (1) conspicuous (rounded).

11. Chelicera, basichelicerite, dorsal distal margin, setalspine, (0) absent; (1) present. 
Table 1.-List of species (outgroup and ingroup) used in the present cladistic analysis with distribution and source of information used (literature or material).

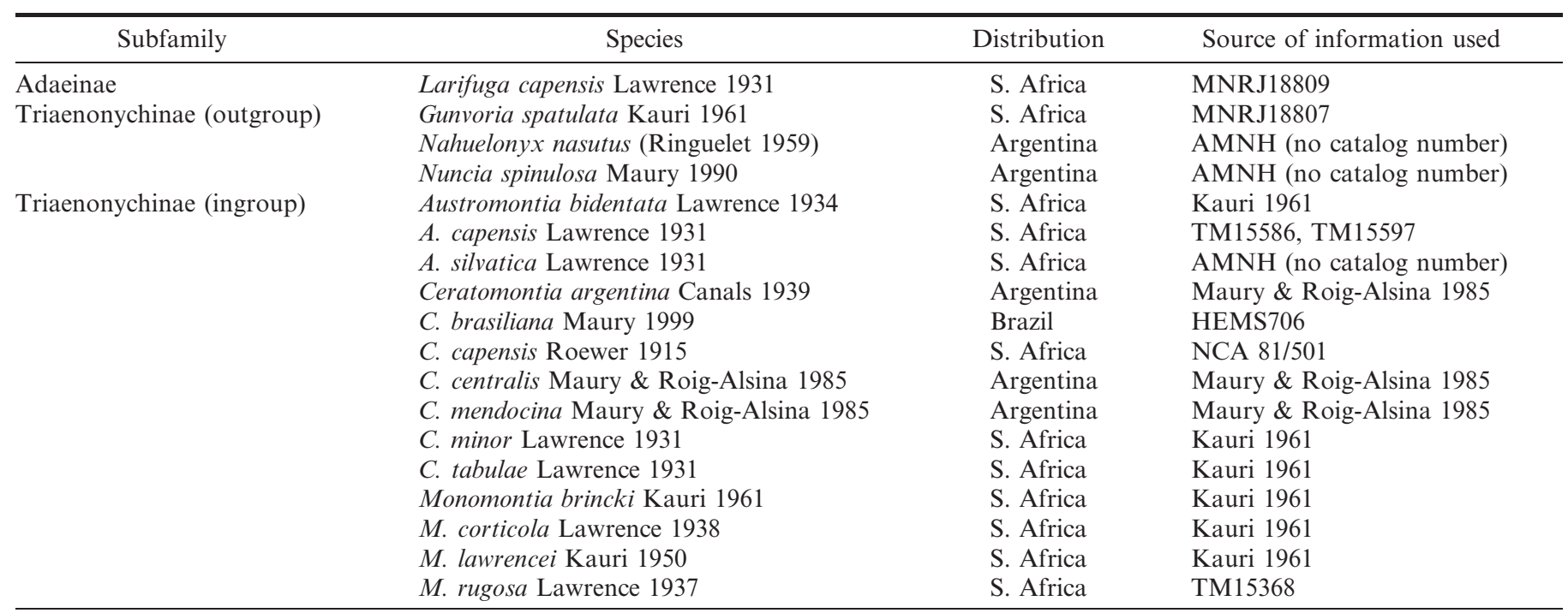

12. Pedipalpal femur, dorsal surface ornamentation, (0) present (Kauri 1961:fig. 45C); (1) absent.

13. Pedipalpal femur, dorsal surface, kind of ornamentation, (0) row of setae; (1) row of flattened tubercles.

14. Pedipalpal femur, dorsal surface, structure and distribution of setae, (0) $\mathrm{fd} 2, \mathrm{fd} 3$ and $\mathrm{fd} 4$ reaching almost the apex (Fig. 1); (1) fd2, fd3, and fd4 reaching half of the femur; (2) fd1-fd5 from basis to the apex.

15. Pedipalpal femur, setae fv3-fv6, (0) all absent; (1) present (at least fv4 and fv6) (Fig. 1).

16. Pedipalpal femur, $f v 1$, length in relation to the other fvs, (0) larger; (1) same size.
17. Pedipalpal femur, fvl aspect, (0) bifid (Lawrence 1931:fig.15d); (1) uniramous (Maury \& Roig-Alsina 1985:figs. 9, 11).

18. Pedipalpal femur, ventral surface, band of small granules, (0) absent; (1) present (Kauri 1961:fig. 49C).

19. Pedipalpal femur, fpl2, (0) absent; (1) present (Lawrence 1931:fig.12C).

20. Pedipalpal femur, shape of the basis of ventral setae, (0) conical (Kauri 1961:fig. 49B); (1) cruciform (Maury \& Roig-Alsina 1985:figs. 1, 3, 5, 7).

21. Pedipalpal tibia, size in relation to the femur, (0) incrassate, comparable size; (1) not incrassate, much smaller.

Table 2.- Character and character state data matrix for selected members of the genera Ceratomontia, Austromontia and Monomontia and outgroup taxa. '-' code for inapplicable, '?' for unavailable, and 'a' for the polymorphism $0+1$.

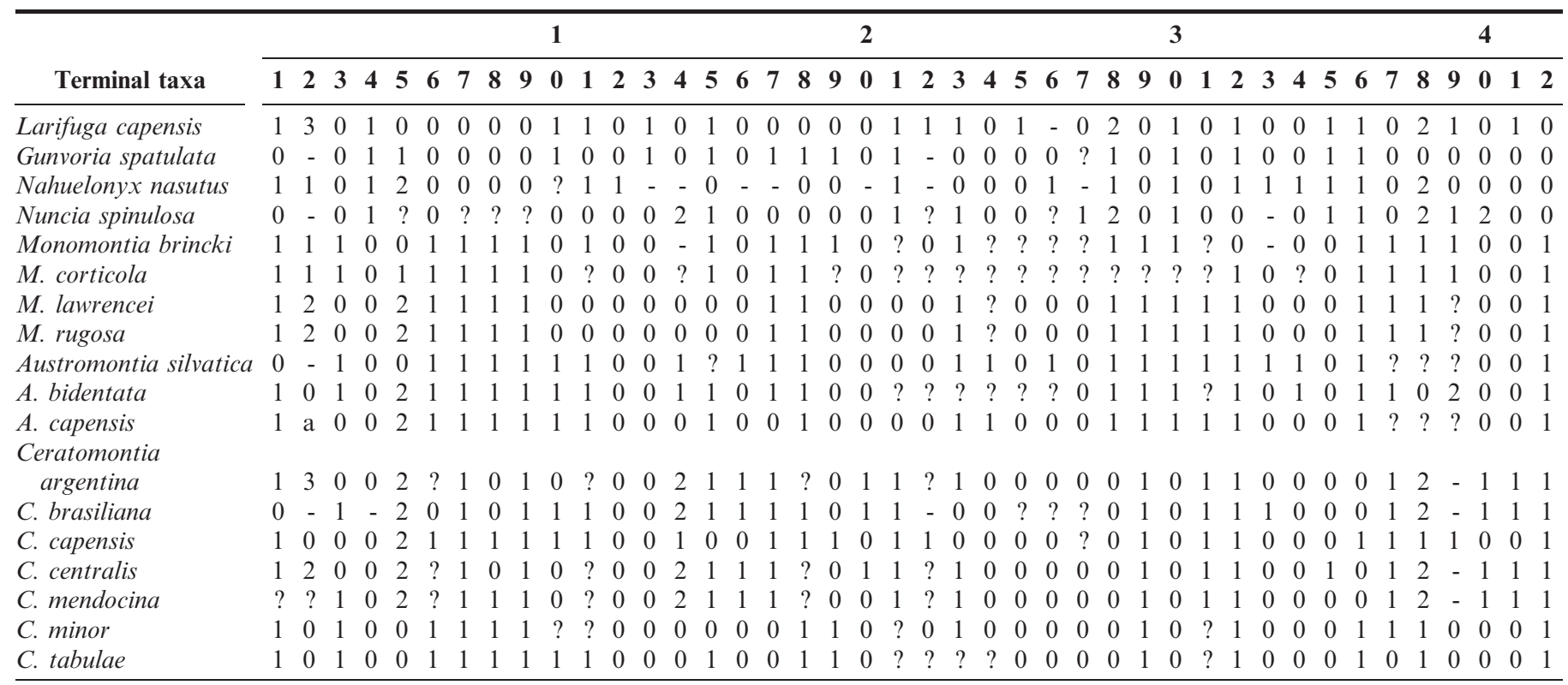




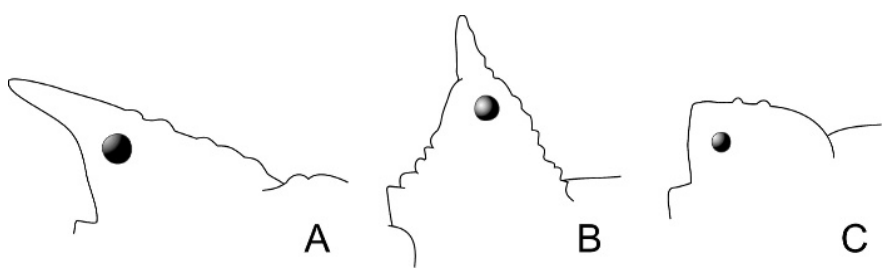

Figure 2.-Triaenonychinae eyemounds, lateral view. A. Monomontia rugosa. B. Larifuga capensis. C. Austromontia silvatica. Not to scale.

22. Pedipalpal tibia, ventral surface, distribution of granules, (0) organized into a mesal row (Lawrence 1931:fig.15b); (1) spread all over the ventral surface.

23. Pedipalpal tibia and tarsus, spine sockets, size, (0) small; (1) conspicuously large (Fig. 1).

24. Pedipalpal tarsus, ectal margin, bifid projection, (0) absent (Lawrence 1931:fig. 15b); (1) present (Lawrence 1931:figs. 29f, 30f).

25. Coxa I, ventral surface aspect, (0) tuberculate; (1) smooth.

26. Coxa I, ventral surface, number of rows of tubercles, (0) one; (1) two.

27. Coxa I, tubercle on the distal margin, aspect of tip, (0) conspicuously bifid (Fig. 3); (1) uniramous

28. Tarsus I, number of tarsomeres, (0) two; (1) three; (2) four.

29. Tarsus II, number of tarsomeres, (0) more than six; (1) less than six.

30. Tarsus III and IV, number of tarsomeres, (0) three; (1) four.

31. Tarsus I, distal tarsomere, size in relation to the other tarsomere (s), (0) similar; (1) incrassate (Maury \& RoigAlsina 1985:figs. 2, 4, 6, 8).

32. Femur I, ventral surface, tubercles organized into a row, (0) absent; (1) present (Lawrence 1931:figs. 12b, 13d, 15d).

33. Femur I, ventral surface, tubercles shape, (0) elongate (Maury \& Roig-Alsina 1985:figs. 2, 4, 6, 8); (1) flattened (granules).

34. Metatarsus I-II, calcaneus, length in relation to the podomere length, (0) less than half (Maury \& Roig-Alsina 1985:figs. 2, 4, 6, 8); (1) about half.

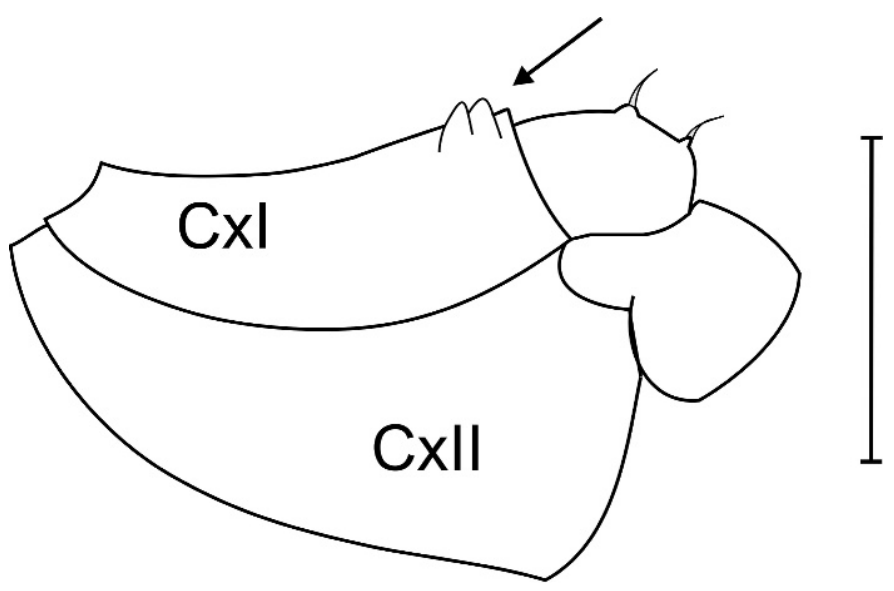

Figure 3.-Austromontia silvatica. Ventral view of the left coxa III. The seta points to the bifid tubercle on the distal margin of coxa I. Scale bar $=1 \mathrm{~mm}$.

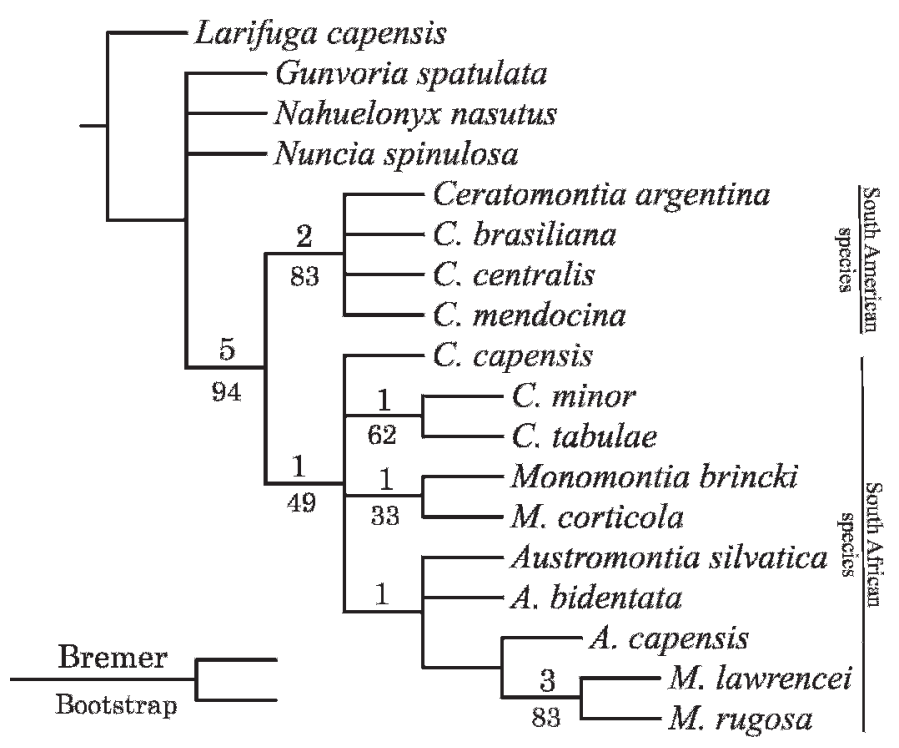

Figure 4.-Summary hypothesis of phylogeny of Ceratomontia and related genera Austromontia and Monomontia: strict consensus of the 12 most-parsimonious trees resulting from the analysis under equal weights at 95 steps $(\mathrm{CI}=0.52, \mathrm{RI}=0.66)$. Clade support is indicated above (Bremer support) and below (bootstrap proportions) branches.

\section{Male genitalia}

35. Dorsal plate, length in relation to the ventral plate, (0) elongate, longer than the ventral plate (Maury \& RoigAlsina 1985:figs. 15, 16); (1) short, about same length or shorter than the ventral plate.

36. Ventral plate, aspect (presence of a deep cleft), (0) entire (without any cleft) (Maury \& Roig-Alsina 1985:fig. 16); (1) divided (with a deep cleft) (Kauri 1961:figs. 49F, 50A, 51A).

37. Dorso-lateral plate, disto-ventral projections, (0) absent; (1) present.

38. Ventral plate, width of basis in relation to the apex, (0) wider (Kauri 1961:fig. 54E); (1) narrower (Kauri 1961:figs. 45A, 46A, 49F, 50A, 51A); (2) same (Maury \& RoigAlsina 1985:fig. 16).

39. Ventral plate halves, shape, (0) rectangular (Kauri 1961:figs. 45A, 46A); (1) oval (rounded); (2) triangular (narrow apex) (Kauri 1961:fig. 54A).

40. Sensilar region, number of setae, (0) 4+4 (Kauri 1961:figs. 45A, 46A, 49F, 50A, 51A, 54A); (1) 5+5 (Maury \& RoigAlsina 1985:figs. 13-16); (2) 3+3.

41. Sensilar region, setae distribution, (0) all ahead (Kauri 1961:figs. 45A, 46A, 49F, 50A, 51A, 54A); (1) a part ahead and the other behind the ventral plate (Maury \& RoigAlsina 1985:figs. 13-16).

42. Stylus position, (0) independent; (1) enfolded by the dorsal plate (Maury \& Roig-Alsina 1985, figs 15-16).

\section{RESULTS}

The analysis under equal weights resulted in 12 most parsimonious trees, with 95 steps, $\mathrm{CI}=0.52, \mathrm{RI}=0.66$. The strict consensus hypothesis (Fig. 4) does not recover a monophyletic Ceratomontia; instead, the South African species form a clade with the Austromontia and Monomontia 


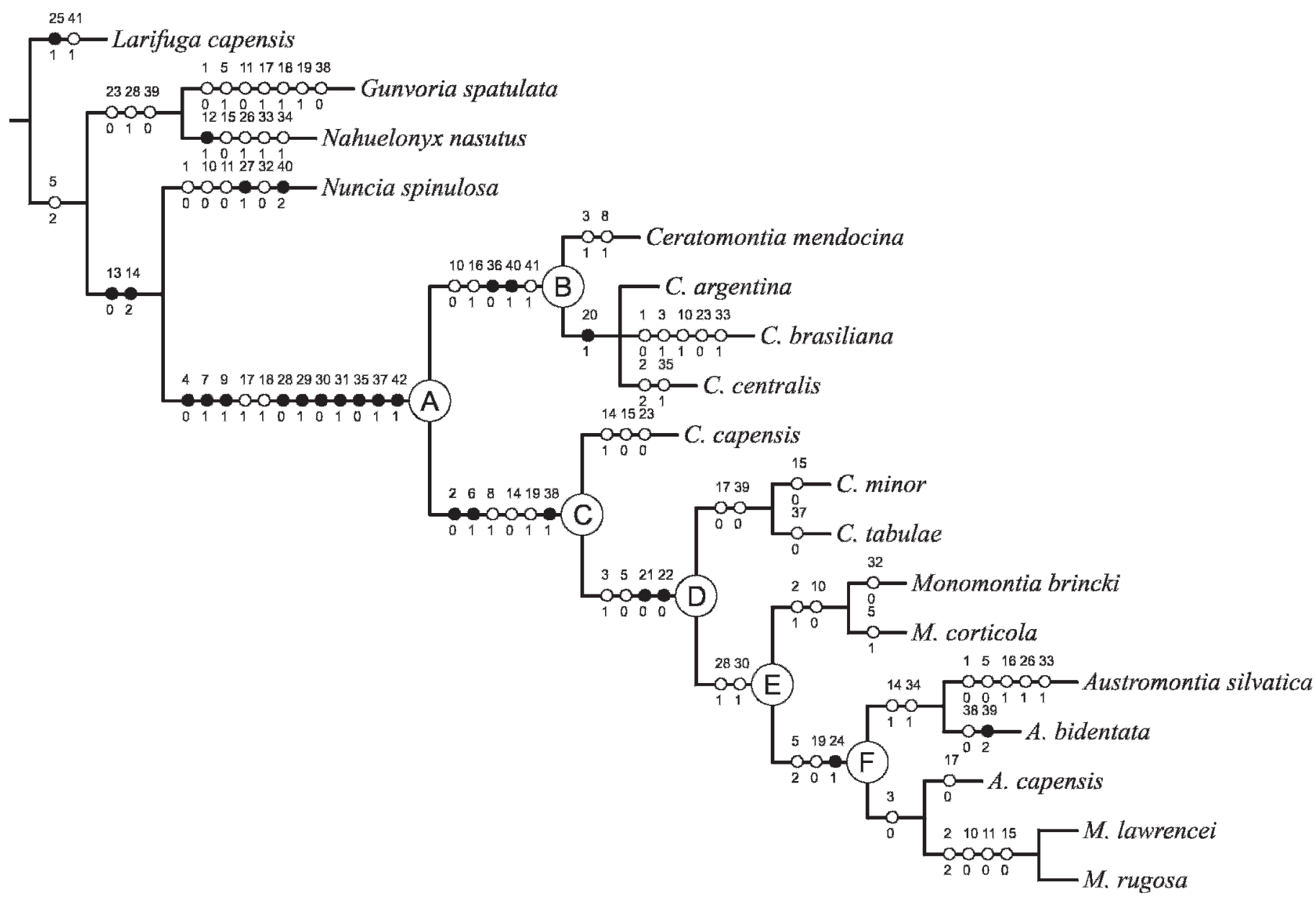

Figure 5.- Preferred hypothesis of phylogeny of Ceratomontia and related genera Austromontia and Monomontia: tree obtained from the analyses under implied weights with all concavities $(k=1-6)$ and one of the most parsimonious trees obtained from the analysis under equal weights. Apomorphies are plotted on branches, black circles indicate non-homoplastic apomorphies, empty circles indicate homoplastic apomorphies and reversals. (See Table 3 for details.) Certain nodes are named with letters (A-F) for usage in the text.

Table 3.-Apomorphy list for the preferred tree (Fig. 5) of the cladistic analysis of the genera Ceratomontia, Austromontia, and Monomontia. The names of the nodes follow Fig. 5. Non-homoplastic synapomorphies are in bold type, A codes ACCTRAN optimization, D codes DELTRAN optimization, and $\mathrm{R}$ reversion.

\begin{tabular}{|c|c|}
\hline Node & Apomorphies \\
\hline (Gunvoria + Nahuelonyx) & $23(0) ; 28(1) ; 39(0)$ \\
\hline$($ Nuncia $+\mathrm{A})$ & $13(0) ; 14(2) A$ \\
\hline A & $\begin{array}{l}\text { 4(0); 7(1)D; 9(1)D; 17(1)D; 18(1); 28(0); 29(1); 30(0); 31(1); 35(0); 37(1), } \\
\text { 42(1)D }\end{array}$ \\
\hline B & 10(0)D;16(1); 36(0); 40(1); 41(1) \\
\hline $\mathrm{C}$ & $\mathbf{2 ( 0 )} ; \mathbf{6}(\mathbf{1}) ; 8(1) \mathrm{D} ; 14(0) \mathrm{AR} ; 19(1) ; \mathbf{3 8}(\mathbf{1})$ \\
\hline $\mathrm{D}$ & $3(1) ; 5(0) A R ; 21(0) A ; 22(0)$ \\
\hline (Ceratomontia argentina $+C$. brasiliana $+C$. centralis $)$ & 20(1) \\
\hline$($ C. minor + C. tabulae $)$ & $17(0) ; 39(0)$ \\
\hline$($ Monomontia brincki + M. corticola $)$ & $2(1) ; 10(0)$ \\
\hline (Austromontia silvatica + A. bidentata) & $14(1) ; 34(1)$ \\
\hline (A. capensis $+(M$. lawrencei $+M$. rugosa $))$ & $3(0) \mathrm{R}$ \\
\hline (M. lawrencei + M. rugosa) & $2(2) ; 10(0) ; 11(0) ; 15(0)$ \\
\hline
\end{tabular}


species. The Ceratomontia species from South America constitute a clade that is the sister-group of the clade composed by the South African species of the ingroup. The analyses under implied weights resulted in the same tree with all concavities analyzed (Fig. 5), which is also one of the 12 trees obtained by the analysis under equal weights. For this reason, this is the hypothesis chosen to show and discuss the distribution and optimization of the characters.

The represented species of Ceratomontia and of the genera Austromontia and Monomontia comprise the monophyletic group (Fig. 5, A) with the highest support in the analysis: $94 \%$ bootstrap support and Bremer support of five. This clade is supported by ten unambiguous synapomorphies (eight in both optimizations, ACCTRAN and DELTRAN) such as the number of tarsomeres of tarsus I-IV (characters 28-30), the elongate dorsal plate of male genitalia (character 35 , state 0 ) and the stylus of male genitalia enfolded by the dorsal plate (character 42, state 1). The clade formed by the South American Ceratomontia species (Fig. 5, B) is supported by two unambiguous synapomorphies, the entire ventral plate in male genitalia (character 36, state 0 ) and the number of male genitalia setae (character 40, state 1). This clade was supported by $83 \%$ of bootstrap replicates. The clade formed by the South African species of Ceratomontia, and the genera Austromontia and Monomontia (Fig. 5, C) is supported by three unambiguous synapomorphies including the shape of the ventral plate of the male genitalia, which is narrower in its basis than in the apex (character 38, state 1). This clade does not have a high support of bootstrap and Bremer support (49\%, 1 respectively). The Ceratomontia species from South Africa appeared paraphyletic, basal in relation to the clade formed by the species of Austromontia and Monomontia (Fig. 5, E). This clade (E) is supported by two synapomorphies (a homoplasy and a reversal, respectively), the number of tarsomeres of tarsus I (character 28, state 1) and tarsus III and IV (character 30 , state 1). Although recovered by the analyses under implied weights, this clade (E) was ambiguously supported by the analysis under equal weights. Some pairs of species appeared as clades in the analysis: $M$. brincki $+M$. corticola, $C$. minor + C. tabulae and M. lawrencei $+M$. rugosa.

\section{DISCUSSION}

The results show that Ceratomontia is indeed involved in a "Gondwanan relationship," although it includes other genera as it is not a monophyletic group. Because of these results, there are ways to interpret the classification: 1) consider all the species of the ingroup as a single genus, Ceratomontia, which has priority over the remaining genera; 2) consider the South African species of Ceratomontia (which includes the type species) and Austromontia and Monomontia species as Ceratomontia and describe a new genus for the South American species.

We are not making nomenclatural acts in the present paper although the clade formed by Ceratomontia, Austromontia, and Monomontia showed a high bootstrap support. We are aware that the case of this "intercontinental" genus is complex. To further clarify the relationships, an analysis with wider representation should be carried out, including more representatives of other genera in the family, especially those from the Ceratomontia group. Moreover, while the South
American species of Ceratomontia (Fig. 5, B) showed reasonable support for description of a new genus, the South African species clade (Fig. 5, C) did not provide equal justification including the present species in one separate genus. Consequently, making nomenclatural changes based on the present analysis would result in a weakly supported Ceratomontia.

One example of the need of including more terminal taxa is the presence of a band of small granules on the ventral surface of the pedipalpal femur appearing as a synapomorphy of the ingroup (character 18, state 1). We know that this character state has a wider distribution as it is also present in other genera of the Ceratomontia group not included in the analysis. Besides, although coded as present for C. brasiliana, actually it is doubtful for the South American species of Ceratomontia. So it could be an eligible synapomorphy of a group formed only by some South African genera of Triaenonychinae.

It would also be necessary to include the type species of Monomontia, M. atra Lawrence 1931, which was not represented in the analysis due to lack of material and detailed descriptions, including male genitalia, in the literature. Therefore, any decision made now could bring more confusion to the case.

\section{ACKNOWLEDGMENTS}

We are thankful to Ansie Dippenaar (NCA), Klaas Manamela (TM), and Norman Platnick (AMNH) for the loan of material. We thank Leonardo Gil-Azevedo (Fiocruz) for many useful suggestions. We also thank Gonzalo Giribet, and the editors Mark Harvey and Paula Cushing for their comments on the manuscript. This study was supported by a Ph.D. scholarship from CAPES to ACM and by a grant from $\mathrm{CNPq}$ to $\mathrm{ABK}$. The Fundação Universitária José Bonifácio (FUJB) and Fundação Vitae contributed to the equipment of the Laboratório de Aracnologia of Museu Nacional/UFRJ.

\section{LITERATURE CITED}

de Bivort, B.L. \& G. Giribet. 2004. A new genus of cyphophthalmid from the Iberian Peninsula with a phylogenetic analysis of the Sironidae (Arachnida : Opiliones : Cyphophthalmi) and a SEM database of external morphology. Invertebrate Systematics $18: 7-52$.

Bremer, K. 1994. Branch support and tree stability. Cladistics 10:295-304.

Canals, J. 1939. Nuevos Opiliones de la Argentina. Notas del Museo de La Plata, Zoología 4:143-156.

Felsenstein, J. 1985. Confidence limits on phylogenies: an approach using the bootstrap. Evolution 39:783-791.

Giribet, G. \& A.B. Kury. 2007. Phylogeny and Biogeography. Pp. 62-87. In Harvestmen: the Biology of the Opiliones. (R. Pinto-da-Rocha, G. Machado \& G. Giribet, eds.). Harvard University Press, Cambridge, Massachusetts.

Goloboff, P.A. 1993a. Pee-Wee. Parsimony and Implied Weights, Version 3.0. Program and documentation available from James M. Carpenter, Department of Entomology, American Museum of Natural History, Central Park West at 79th Street, New York, New York 10024

Goloboff, P.A. 1993b. Estimating character weights during tree search. Cladistics 9:83-91.

Goloboff, P. 1993c. NONA (a bastard son of Pee-Wee). Version 2.0. Program and documentation. Online at http://www.cladistics.com.

Hunt, G.S. \& J.L. Hickman. 1993. A revision of the genus Lomanella Pocock and its implications for family level classification in the Travunioidea (Arachnida: Opiliones: Triaenonychidae). Records of the Australian Museum 45:81-119. 
Kauri, H. 1961. Opiliones. Pp. 9-197. In South African Animal Life. Results of the Lund University Expedition in 1950-1951. (B. Hanström, P. Brinck \& G. Rudebeck, eds.), Volume 8. Almquist \& Wiksell, Uppsala

Kury, A.B. 2003. Annotated catalogue of the Laniatores of the New World (Arachnida, Opiliones). Revista Ibérica de Aracnología, vol. especial monográfico, $\mathrm{n}^{\circ}$ 1:1-337.

Lawrence, R.F. 1931. The harvest-spiders (Opiliones) of South Africa. Annals of the South African Museum 29:341-508.

Lawrence, R.F. 1934. New South African Opiliones. Annals of the South African Museum 30:549-586.

Lawrence, R.F. 1937. A collection of Arachnida from Zululand. Annals of the Natal Museum 8:211-273.

Martens, J. 1986. Die Grossgliederung der Opiliones und die Evolution der Ordnung (Arachnida). Pp. 289-310. In Actas del X Congreso Internacional de Aracnología, Jaca, Espagña. (J.A. Barrientos, ed.), Volume 1. Instituto Pirenaico de Ecologia \& Grupo de Aracnología, Barcelona.

Maury, E.A. 1999. Triaenonychidae sudamericanos. VIII. El género Ceratomontia en el Brasil (Opiliones: Laniatores). Revista de la Sociedad Entomológica Argentina 58:33-36.

Maury, E.A. \& A.H. Roig-Alsina. 1985. Triaenonychidae Sudamericanos. I. El genero Ceratomontia Roewer 1915 (Opiliones: Laniatores). Historia Natural 5:77-92.

Nixon, K.C. 2002. WinClada. Version 1.00.08. Program and documentation. Online at http://www.cladistics.com.

Nixon, K.C. \& J.M. Carpenter. 1993. On outgroups. Cladistics 9:413-426.

Prendini, L. 2003. A new genus and species of bothriurid scorpion from the Brandberg Massif, Namibia, with a reanalysis of bothriurid phylogeny and a discussion of the phylogenetic position of Lisposoma Lawrence. Systematic Entomology 28:149-172.

Roewer, C.-F. 1915. Die Familie der Triaenonychidae der Opiliones Laniatores. Archiv für Naturgeschichte, Abteilung A, OriginalArbeiten 80(12):61-168.

Roewer, C.-F. 1923. Die Weberknechte der Erde. Systematische Bearbeitung der bisher bekannten Opiliones. Gustav Fischer, Jena. $1116 \mathrm{pp}$

Shear, W.A. 1977. Fumontana deprehendor, n. gen., n. sp., the first triaenonychid opilionid from eastern North America (Opiliones: Laniatores: Triaenonychidae). Journal of Arachnology (1975) 3:177-183.

Shear, W.A. 1978. A new record for the rare opilionid Fumontana deprehendor (Opiliones, Triaenonychidae). Journal of Arachnology (1974) 6:79.

Starega, W. 1992. An annotated check-list of harvestmen, excluding Phalangiidae, of the Afrotropical Region (Opiliones). Annals of the Natal Museum 33:271-336.

Thomas, S.M. \& M. Hedin. 2006. Natural history and distribution of the enigmatic southern Appalachian opilionid, Fumontana deprehendor Shear (Laniatores: Triaenonychidae), with an assessment of morphological variation. Zootaxa 1242:21-36.

Turner, H. \& R. Zandee. 1995. The behaviour of Goloboff's tree fitness measure $F$. Cladistics 11:57-72.

Wheeler, W.C. 1995. Sequence alignment, parameter sensitivity, and the phylogenetic analysis of molecular data. Systematic Biology 44:321-331.

Manuscript received 5 December 2007, revised 31 March 2008. 